\title{
Room Temperature Ionic Liquids \\ as Replacements for Organic Solvents: \\ Direct Preparation of Wholly Aromatic Polyamides \\ Containing Phthalimide and S-valine Moieties
}

\author{
By Shadpour MALLAKPOUR* and Majid KOLAHDOOZAN
}

\begin{abstract}
Ionic liquids (IL)s are often considered as green solvents capable of replacing traditional organic solvents and have extensively studied in material chemistry and catalysis. In this work a new class of wholly aromatic and optically active polyamides (PAs) having phthalimide and S-valine pendent groups were prepared by the reaction of 5-(2-phthalimidyl-3methylbutanoylamino)isophthalic acid as a diacid monomer with various aromatic diamines. ILs media in the presence of triphenyl phosphite was used as a condensing agent. The resulting novel optically active PAs with inherent viscosities ranging from $0.35-0.71 \mathrm{dLg}^{-1}$, were obtained in excellent yields. This method of polymerization was also compared with direct polyamidation using conventional phosphorylation reaction. Introduction of bulky and flexible clusters in these polymers pendent group, make them readily soluble in most organic solvents. The resulting polymers show optical rotation, therefore, are optically active.

KEY WORDS: Ionic Liquid / Polyamides / Green Chemistry / Optically Active Polymers / Direct Polycondensation /
\end{abstract}

Ionic liquids (IL)s may be sighted as a new and remarkable class of solvents, or as a type of materials that have useful history. ILs are either organic salts or mixtures of salts that are fluid at room or near-room temperature. ${ }^{1}$ Research teams in industrial and academic are trying to redesign chemical processes to reduce or eliminate losses of solvents, particularly volatile organic solvents (VOS)s. Obviously, replacement of a VOS in a process with non-volatile solvent will reduce losses through evaporation. It is important that ILs are the chemicals that can be applied as solvents and catalysts in green chemistry processes. Non-volatility of ILs is an important property, but an interest in ILs arises also from other properties. ILs dissolve many organic but what is even more important many inorganic and metaloorganic compounds. ${ }^{2}$ On the other hand, many organic reactions were performed in ILs with particular advantages. Several articles and reviews deals to the study and application of ILs as solvents, asymmetric synthesis, homogeneous catalysts, heterogeneous catalysts and bio catalysts media show the importance and growing role of the ILs in chemistry. ${ }^{1-6}$

The synthesis of polymers in ILs media is also of significant scientific interest. ${ }^{7}$ Recently many kinds of polymerizations were performed in ILs, e.g., free radical, ${ }^{8}$ atom transfer radical,, 910 ring opening polymerization ${ }^{11}$ and polycondensation. ${ }^{12-14}$ ILs play the role of both catalyst and solvent for polycondensation. The polyamidation in ILs proceed as one pot path-way using the free dicarboxylic acid, diamines and have the advantages of direct polycondensation. Therefore, it seems reasonable that ILs may enhance polymer syntheses as well.
Wholly aromatic polyamides (PA)s are known for their excellent thermal and mechanical properties, which make them useful as high-performance materials. But, the poor solubility and high softening or melting temperatures caused by the high crystallinity and high stiffness of the PAs backbone lead to difficult processability of them. So, the applications of PAs are sometimes restricted because of difficulty in their fabrication. ${ }^{15-17}$

Much effort has been made to modify aromatic polymers having better characterization in terms of both solubility and processability with protection of their high thermal stability. Introduction of flexible chains into the polyamide backbone, ${ }^{18}$ the use of meta-oriented or asymmetrically substituted monomers, ${ }^{19,20}$ synthesis of cardo polymers, ${ }^{21}$ synthesis of polyamides (PAs) with noncoplaner unit in the polymer chains, ${ }^{22}$ preparation of copolymers such as poly(amide-imide)s, ${ }^{23-25}$ poly(amide-ester)s, ${ }^{26}$ and poly(amide-ester-imide) $\mathrm{s}^{27}$ resulted in a number of modified polyamides. The other strategy is the introducing of bulky side groups. The solubility of polymers is often improved when flexible bonds, large pendent groups or polar substituents are included into the polymer backbone. If the pendent groups are carefully chosen, it is likely to increase solubility without affecting thermal and mechanical properties to any great extent. These modifications work by breaking the chain symmetry and regularity and by destroying hydrogen bonds and generally lead to lower transition temperatures and better solubility. ${ }^{28-32}$ In many cases, the introduction of diverse heterocyclic rings into the chains of polyamides led to polymers with improved solubility and enhanced thermal stability. ${ }^{32-35}$ 
In the history of polymer science, both naturally occurring and synthetic optically active polymers (OAP)s have received much attention in conjunction with their stereochemistry, and extensive studies have been conducted on their syntheses, conformations and functions. ${ }^{36,37}$ Recent advances in asymmetric reactions and catalysis as well as in chiral separations have afforded a rapid increase in the number of optically active compounds and reagents. ${ }^{38,39}$ This situation will influence new methodologies for the preparation of OAPs.

Herein we wish to demonstrate the successful application of ILs for green synthesis of wholly aromatic optically active PAs containing S-valine amino acid and phthalimide groups in the side chain of the polymers. The bulky side chains disturb the interchain interaction and reduce packing efficiency and crystallinity. Therefore, these polymers may show good solubility. In this study we used ILs as a media for direct polyamidation.

\section{EXPERIMENTAL}

\section{Materials}

All chemicals were purchased from Fluka Chemical Co. (Buchs, Switzerland), Aldrich Chemical Co. (Milwaukee, WI), Riedel-deHaen AG (Seelze, Germany) and Merck Chemical Co. 4,4'-Diaminodiphenylsulfone (2a) was used as obtained without further purification. Benzidine (2d) and 4,4'diaminodiphenyl methane $(\mathbf{6 c})$ were purified by recrystallization from ethanol and water respectively. 4,4'-Diaminodiphenylether (6b), p-phenylenediamine (6e), $m$-phenylenediamine (6f) and 2,5-diaminotoluene (6g) were purified by sublimation. ILs were prepared according to the literature procedure. $^{14}$

\section{Apparatus}

Proton nuclear magnetic resonance $\left({ }^{1} \mathrm{H}\right.$ NMR, $\left.500 \mathrm{MHz}\right)$ spectra were recorded in dimethyl sulfoxide- $\mathrm{d}_{6}\left(\right.$ DMSO- $\left._{6}\right)$ solution using a Bruker (Germany) Avance 500 instrument at Sharif University of Technology, Tehran, Iran. FT-IR spectra were recorded on (Jasco-680, Japan) spectrophotometer. The spectra of solids were obtained using $\mathrm{KBr}$ pellets. The vibrational transition frequencies are reported in wave numbers $\left(\mathrm{cm}^{-1}\right)$. Band intensities are assigned as weak $(\mathrm{w})$, medium (m), shoulder (sh), strong (s) and broad (br). Inherent viscosities were measured by using a Cannon-Fenske Routine Viscometer (Germany) at concentration of $0.5 \mathrm{~g} / \mathrm{dL}$ at $25^{\circ} \mathrm{C}$. Specific rotations were measured by a Jasco Polarimeter (Japan). Thermal gravimetric analysis (TGA) data for polymers were taken on Perkin Elmer in nitrogen atmosphere at a rate of $10{ }^{\circ} \mathrm{C} / \mathrm{min}$. Elemental analyses were performed by the Iran Polymer and Petrochemical Research Institute, Tehran, Iran.

\section{Monomer Synthesis}

5-(2-Phthalimidyl-3-methylbutanoylamino)isophthalic acid (1) as a diacid monomer was prepared according to our pervious published paper. ${ }^{40}$

\section{Polymer Syntheses}

Method I: Direct Polycondensation in ILs. PAs were prepared by the following procedure. For example; for the synthesis of PA1, into a $25 \mathrm{~mL}$ round-bottom flask a mixture of $0.100 \mathrm{~g}$ $\left(2.44 \times 10^{-4} \mathrm{~mol}\right)$ of dicarboxylic acid 1 and $0.061 \mathrm{~g}(2.44 \times$ $10^{-4} \mathrm{~mol}$ ) of diamine $\mathbf{2 a}$ were dissolved in $0.20 \mathrm{~g}$ of $\mathbf{I L}$ (1,3-dipropylimidazolium bromide) under heating. $0.13 \mathrm{~mL}$ $\left(4.88 \times 10^{-4} \mathrm{~mol}\right)$ of triphenyl phosphite (TPP) was added. The mixture was heated at $110^{\circ} \mathrm{C}$ for $5 \mathrm{~h}$. As the reaction proceeded, the solution became viscous. After cooling, the resulting polymer was isolated by the addition of $30 \mathrm{~mL}$ methanol followed by filtration. The product was dried under vacuum to give $0.151 \mathrm{~g}$ of PA1 (94\% yield). The inherent viscosity of the resulting polyamide in DMF was $0.71 \mathrm{dLg}^{-1}$, measured at a concentration of $0.5 \mathrm{gdL}^{-1}$ at $25^{\circ} \mathrm{C}$.

Method II: Direct Polycondensation Phosphorylation Reaction. A mixture of $0.100 \mathrm{~g}\left(2.44 \times 10^{-4} \mathrm{~mol}\right)$ of dicarboxylic acid $\mathbf{1}$, $0.061 \mathrm{~g}\left(2.44 \times 10^{-4} \mathrm{~mol}\right)$ of diamine $\mathbf{2 a}, 0.128 \mathrm{~mL}$ of TPP, $0.1 \mathrm{~mL}$ of pyridine (Py), $0.08 \mathrm{~g}$ of calcium chloride and $0.5 \mathrm{~mL}$ of $N$-methyl-2-pyrrolidone (NMP) was refluxed for $5 \mathrm{~h}$. After cooling, the reaction mixture was poured into $30 \mathrm{~mL}$ of methanol with constant stirring, and the precipitate was washed thoroughly with methanol and hot water, collected on a filter, and dried under vacuum to give $0.1478 \mathrm{~g}$ of PA9 (92\% yield). The inherent viscosity of the resulting polyamide in DMF was $0.45 \mathrm{dLg}^{-1}$, measured at a concentration of 0.5 $\mathrm{gdL}^{-1}$ at $25^{\circ} \mathrm{C}$.

\section{PA1}

FT-IR (KBr): 3316 (br), 2964 (w), 1764 (m), 1719 (s), 1665 (s), 1590 (s), 1528 (s), 1491 (m, sh), 1401 (m), 1385 (w), 1317 (m), $1250(\mathrm{~m}), 1183(\mathrm{w}), 1152(\mathrm{~m}), 1105(\mathrm{~m}), 1072(\mathrm{~m}), 1024(\mathrm{w})$, $951(\mathrm{~m}), 915(\mathrm{~m}), 838(\mathrm{~m}), 755(\mathrm{~m}), 719(\mathrm{~m}) \mathrm{cm}^{-1}$.

PA2

FT-IR (KBr): 3314 (br), 2965 (w), 1768 (m), 1714 (s), 1667 (s), 1598 (s), 1528 (m, sh), 1498 (s), 1405 (m), 1383 (m), 1331 (w), 1227 (s), 1167 (w), 1071 (m), 1013 (w), 880 (w), 832 (m), 719 (m) $\mathrm{cm}^{-1}$.

\section{PA3}

FT-IR (KBr): 3299 (br), 2965 (w), 1768 (m), 1715 (s), 1662 (s), 1595 (s), 1512 (s, sh), 1467 (w), 1444 (w), 1408 (m), 1383 (m), 1318 (m), 1247 (m, sh), 1071 (m, sh), 1019 (w), 888 (m, sh), $814(\mathrm{w}), 720(\mathrm{~m}) \mathrm{cm}^{-1}$.

PA4

FT-IR (KBr): 3305 (br), 2965 (w), 1768 (m), 1714 (s), 1666 (s), 1593 (s), 1501 (s, sh), 1468 (w), 1413 (w), $1384(\mathrm{~m}), 1322(\mathrm{~m})$, 1241 (m), $1114(\mathrm{w}), 1069(\mathrm{~m}), 1004$ (m, sh), 959 (w), 887 (m), $820(\mathrm{~m}), 719(\mathrm{~m}) \mathrm{cm}^{-1}$.

\section{PA5}

FT-IR (KBr): 3303 (br), 2965 (w), 1767 (m), 1713 (s), 1667 (s), 1597 (s), 1513 (s, sh), 1467 (w), 1445 (w), 1384 (m, sh), 1313 (m), 1240 (m), 1075 (m, sh), 1019 (w), 890 (m), 834 (m), 720 (m) $\mathrm{cm}^{-1}$.

PA6

FT-IR (KBr): 3303 (br), 2965 (w), 1766 (m), 1714 (s), 1669 (s), 1605 (s), 1541 (s), 1487 (m), 1443 (w), 1384 (m), 1328 (m), 1242 (m), 1078 (s), 1024 (w, sh), 889 (s), 720 (m) cm $\mathrm{cm}^{-1}$. 


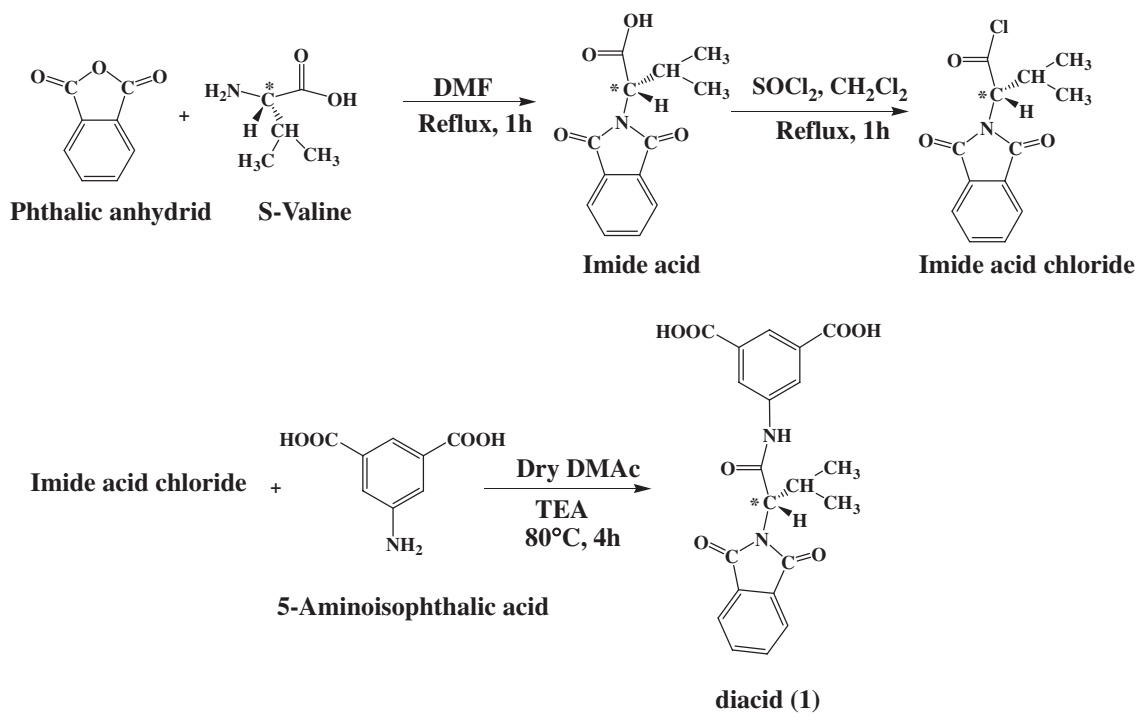

Scheme 1. Synthesis of 5-(2-phthalimidyl-3-methylbutanoylamino)isophthalic acid (1).

\section{PA7}

FT-IR (KBr): 3298 (br), 2964 (w), 1768 (w), 1711 (s), 1669 (s), 1594 (s), 1529 (s, sh), 1444 (m), 1384 (m), 1325 (m), 1242 (m, sh), 1078 (m, sh), 892 (m), $821(\mathrm{w}), 749(\mathrm{~m}), 721(\mathrm{~m}) \mathrm{cm}^{-1}$. PA8

FT-IR (KBr): 3289 (br), 2965 (w), 1769 (m), 1715 (s), 1661 (s), 1595 (s), 1531 (s), 1492 (m), 1444 (w), 1412 (w), 1384 (m), 1334 (m), 1269 (w, sh), 1236 (m), 1069 (m), 1010 (w), 959 (w), $887(\mathrm{~m}), 783(\mathrm{~m}), 754(\mathrm{~m}), 719(\mathrm{~m}) \mathrm{cm}^{-1}$.

\section{RESULTS AND DISCUSSION}

\section{Syntheses of Monomer}

The 5-(2-phthalimidyl-3-methylbutanoylamino)isophthalic acid (1) as a diacid monomer was synthesized in three steps as reported previously (Scheme 1). ${ }^{40}$

\section{Syntheses of Polyamides}

In order to prepare PAs in ILs, first the reaction of monomer 1 with diamine 2a was carried out in different ILs bearing different alkyl groups (Table I). The best inherent viscosity and yield was obtained when 1,3-dipropylimidazolium bromide used as IL for direct polycondensation (Table I, PA1a). So 1,3dipropylimidazolium bromide was used for other polymerization reactions. Table II shows the selected conditions for polyamidation reactions in ILs.

Two different methods (method I and II) were used for the direct polycondensation of dicarboxylic acid $\mathbf{1}$ with various diamines. In the method I, the ILs in the presence of TPP promotes polyamidation reaction, and in method II direct polycondensations of selected diamines were carried out by phosphorylation reaction using NMP/TPP/Py as a condensing agent (Scheme 2). In method II, $\mathrm{CaCl}_{2}$ was also added to the reaction mixture and the polymerization proceeded homogenously.
Table I. The effects of type of ILs on yeild and inherent viscosity of the PA1 ${ }^{\text {a }}$

\begin{tabular}{|c|c|c|c|}
\hline Polymer code & IL & Yield (\%) & $\eta_{\text {inh }}(\mathrm{dL} / \mathrm{g})$ \\
\hline PA1a & & 94 & 0.71 \\
\hline PA1b & & 90 & 0.57 \\
\hline PA1c & & 80 & 0.42 \\
\hline PA1d & & 78 & 0.48 \\
\hline PA1e & & 82 & 0.35 \\
\hline PA1f & & 76 & 0.38 \\
\hline
\end{tabular}

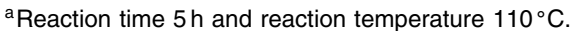

Table II. Reaction conditions for polymerization in ILs
IL

TPP/monomer (mmol/mmol)

Reacion time $(\mathrm{h})$

Reaction temperature $\left({ }^{\circ} \mathrm{C}\right)$

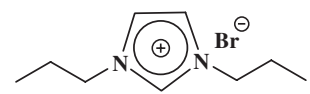

2

5
PAs from method I were obtained in excellent yields (yields were above 90\%), had inherent viscosity values ranging between $0.35-0.71 \mathrm{dLg}^{-1}$ and had bright color (Table III). In method II, PA9 and PA10 were obtained with almost lower yields in compare to PA1 and PA4 which were prepared by method I with same diamines, respectively. Table III also 

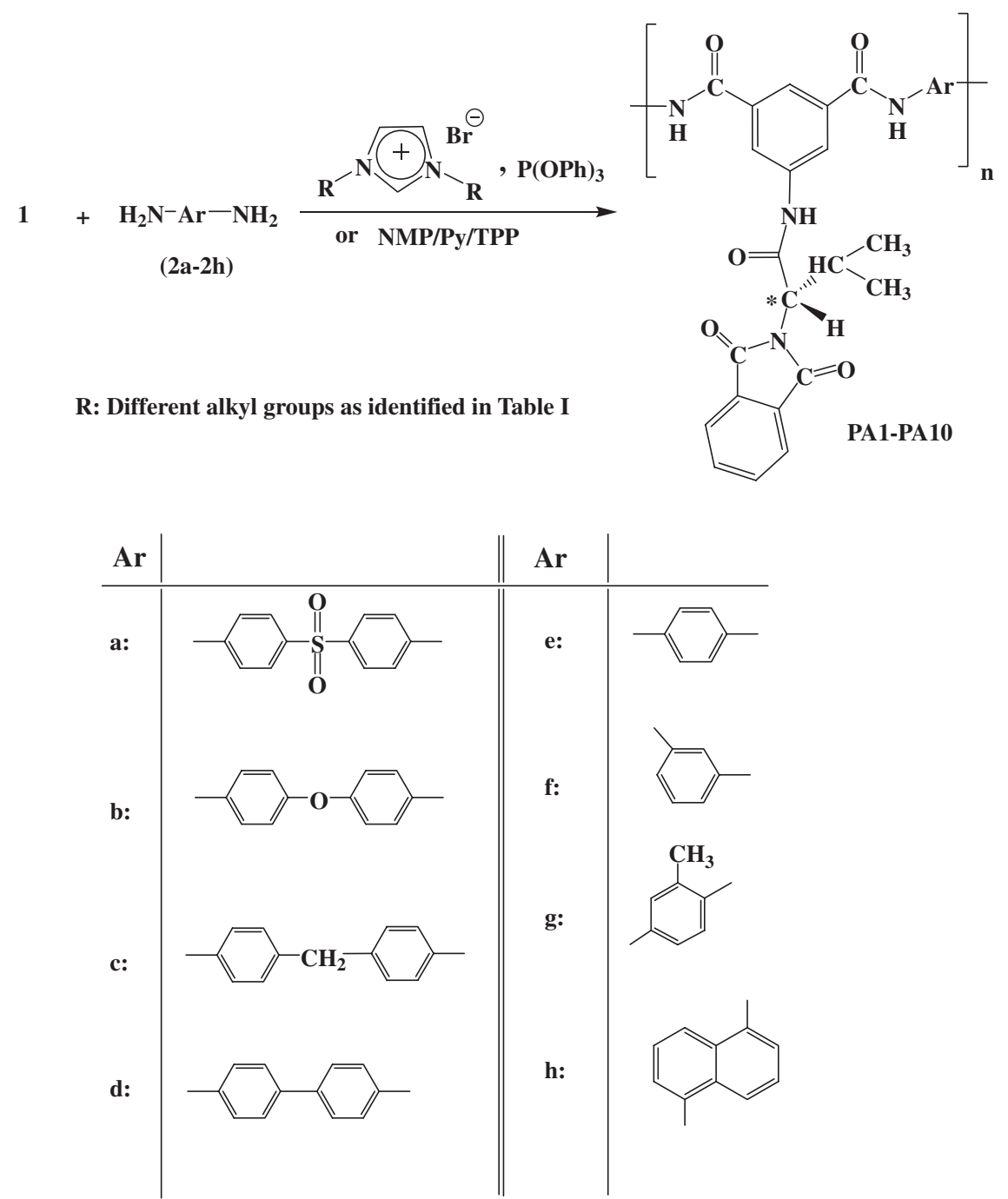

Scheme 2. Direct polyamidation reactions of monomer 1 with various aromatic diamines in ILs and phosphorylation reaction.

Table III. Synthesis and some physical properties of PA1-PA10

\begin{tabular}{|c|c|c|c|c|c|c|c|c|}
\hline \multirow[b]{2}{*}{ Diamine } & \multicolumn{8}{|c|}{ Polymer } \\
\hline & Polymer & $\begin{array}{c}\text { Method of } \\
\text { Polymerization }\end{array}$ & $\begin{array}{l}\text { Yield } \\
(\%)\end{array}$ & $\begin{array}{c}\eta_{\text {inh }} \\
(\mathrm{dL} / \mathrm{g})^{\mathrm{b}}\end{array}$ & {$[\alpha]_{\mathrm{Na}, 589}^{25, c}$} & {$[\alpha]_{H g}^{25, c}$} & Color & $\begin{array}{c}\text { Film } \\
\text { Properties }^{\mathrm{e}}\end{array}$ \\
\hline $2 a$ & PA1a & $I$ & 94 & 0.71 & -52.44 & -82.70 & White & Flexible \\
\hline $2 b$ & PA2 & I & 90 & 0.43 & -17.44 & -24.82 & $\begin{array}{l}\text { Pale } \\
\text { yellow }\end{array}$ & Brittle \\
\hline 2c & PA3 & I & 99 & 0.40 & -12.88 & -20.16 & Yellow & Brittle \\
\hline $2 d$ & PA4 & I & 98 & 0.67 & -14.86 & -29.02 & Yellow & Flexible \\
\hline $2 e$ & PA5 & I & 97 & 0.53 & -16.40 & -21.82 & White & Brittle \\
\hline $2 f$ & PA6 & I & 94 & 0.35 & -14.42 & -15.86 & Yellow & Brittle \\
\hline $2 \mathrm{~g}$ & PA7 & I & 92 & 0.44 & -11.36 & -32.58 & $\begin{array}{l}\text { Pale } \\
\text { yellow }\end{array}$ & Flexible \\
\hline $2 \mathrm{~h}$ & PA8 & I & 97 & 0.41 & -7.50 & -30.56 & White & Brittle \\
\hline $2 a$ & PA9 & II & 92 & 0.45 & $-^{d}$ & -13.92 & $\begin{array}{c}\text { Off } \\
\text { white }\end{array}$ & Brittle \\
\hline $2 d$ & PA10 & II & 94 & 0.74 & -34.10 & -60.18 & $\begin{array}{c}\text { Off } \\
\text { white }\end{array}$ & Brittle \\
\hline
\end{tabular}

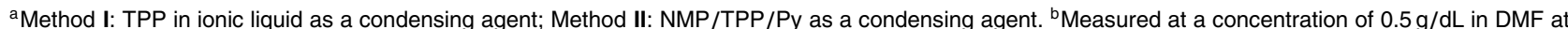
$25^{\circ} \mathrm{C}$. ' Measured at a concentration of $0.5 \mathrm{~g} / \mathrm{dL}$ in DMF at $25^{\circ} \mathrm{C}$. ${ }^{\mathrm{d}}$ not observed. ${ }^{\mathrm{e}}$ Film formed by evaporation of solvent from polymer solution in DMF. 
Table IV. Elemental Analysis of typical PA1, PA2

\begin{tabular}{ccccccc}
\hline \multirow{2}{*}{$\begin{array}{c}\text { Polymer } \\
\text { code }\end{array}$} & Formula & & \multicolumn{3}{c}{ Elemental Analysis (\%) } & $\begin{array}{c}\text { Moisture } \\
\text { Intake(\%) }\end{array}$ \\
\cline { 3 - 5 } & & & $\mathrm{C}$ & $\mathrm{H}$ & $\mathrm{N}$ & \multirow{2}{\text{a}}{ PA1 } \\
\cline { 3 - 5 } & $\mathrm{C}_{33} \mathrm{H}_{26} \mathrm{~N}_{4} \mathrm{O}_{7} \mathrm{~S}$ & Calcd & 63.66 & 4.21 & 9.00 & 3.4 \\
& $(622.15)_{\mathrm{n}}$ & Found & 61.25 & 4.44 & 8.33 & \\
& & Corr & 63.34 & 4.28 & 8.61 & \\
PA2 & $\mathrm{C}_{33} \mathrm{H}_{26} \mathrm{~N}_{4} \mathrm{O}_{6}$ & Calcd & 68.98 & 4.56 & 9.75 & 2.3 \\
& $(574.18)_{\mathrm{n}}$ & Found & 67.18 & 4.69 & 9.30 & \\
& & Corrb & 68.72 & 4.58 & 9.52 & \\
\hline
\end{tabular}

a Moisture Intake $(\%)=\left(\mathrm{W}-\mathrm{W}_{0}\right) / \mathrm{W}_{0} \times 100, \mathrm{~W}=$ weight of polymer sample after standing at room and $\mathrm{W}_{0}=$ weight of polymer sample after dried in vacuum at $100^{\circ} \mathrm{C}$ for $10 \mathrm{~h}$. ${ }^{\mathrm{b}}$ Corrected value for $\mathrm{C}, \mathrm{N}$ and $\mathrm{S}=$ Found value $\times(100+$ moisture intake $) / 100$, and Corrected value for $\mathrm{H}=$ Found value $\times(100-$ moisture intake $) / 100$.

shows that PA1 has higher inherent viscosity than PA9, but the inherent viscosities of PA4 and PA10 are comparable. The main advantage of the method $\mathbf{I}$ is that, in this procedure, the volatile and toxic solvents such as NMP, Py and extra material such as $\mathrm{CaCl}_{2}$ are not required to be used and the reaction is eco-friendly and green. In addition high temperature polymerization reaction which was used in phosphorylation reaction (reflux condition) may slightly decompose the resulting polymers or even cause to break the chains, but this problem in ILs method is lower, since polymerization temperature in ILs is much lower $\left(110^{\circ} \mathrm{C}\right)$. It is very interesting to mention that, in method $\mathbf{I}$, the polymers were not obtained in the absence of either ILs or TPP, so the presence of both components are necessary for polyamidation reactions, and consequently ILs play as a catalyst as well as solvent for these reactions.

The structure of PAs was confirmed by elemental analysis, FT-IR and ${ }^{1} \mathrm{H}$ NMR spectroscopy techniques. Films were formed by evaporation of solvent from polymer solutions in $\mathrm{N}, \mathrm{N}$-dimethylformamide (DMF). The incorporation of chiral unit into polymer backbone was confirmed by measuring their specific rotation (Table III). The specific rotations of polymers based different diamines showed random changes. These observations are the result of different polymers' structure and inherent viscosity. All of the PAs show optical rotation and therefore are optically active.

Elemental analysis data of two typical PAs are listed in the Table IV. The chemical structures of these newly synthesized polymers were confirmed by the good agreement of the elemental analysis values with those of the calculated values.

\section{Polymer Characterizations}

FT-IR Study. The structures of these polymers were confirmed as PAs by means of FT-IR spectroscopy. The FT-IR spectral data of polymer PA1-PA8 are listed in the experimental section. The FT-IR spectra of all polymers showed absorptions around $3300 \mathrm{~cm}^{-1}(v \mathrm{~N}-\mathrm{H}), 1765 \mathrm{~cm}^{-1}(v \mathrm{C}=\mathrm{O}$ asymmetric, imide $), 1710 \mathrm{~cm}^{-1}(v \mathrm{C}=\mathrm{O}$ symmetric, imide $), 1670 \mathrm{~cm}^{-1}$ ( $v \mathrm{C}=\mathrm{O}$, amide). All of these PAs exhibited absorption at $1380-1385 \mathrm{~cm}^{-1}$ ( $v \mathrm{C}-\mathrm{N}$, imide) and $715-725 \mathrm{~cm}^{-1}$ that show the presence of the imide heterocycle in these polymers. The PA1 showed characteristic absorptions at $1250,1152 \mathrm{~cm}^{-1}$ due to the sulfone moiety ( $\mathrm{SO}_{2}$ stretching).

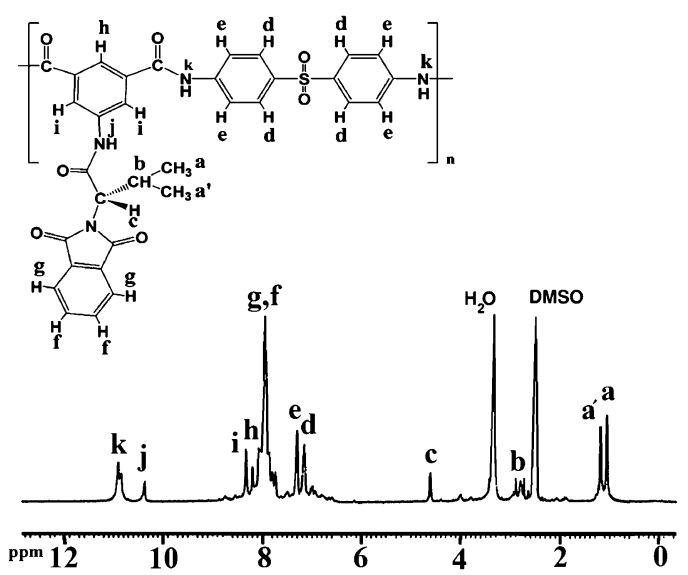

Figure 1. ${ }^{1} \mathrm{H}$ NMR $(500 \mathrm{MHz})$ spectrum of PA1 in DMSO- $\mathrm{d}_{6}$ at rt.

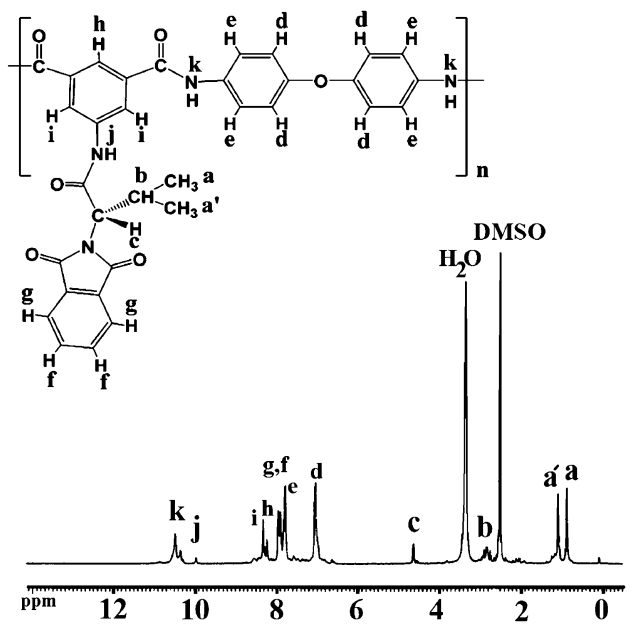

Figure 2. ${ }^{1} \mathrm{H}$ NMR $(500 \mathrm{MHz})$ spectrum of PA2 in DMSO- $\mathrm{d}_{6}$ at rt.

${ }^{1}$ H NMR Study. Figures 1 and 2 show the ${ }^{1} \mathrm{H}$ NMR (500 $\mathrm{MHz}$ ) spectra of polymers PA1, PA2. In the ${ }^{1} \mathrm{H}$ NMR spectra of these two polymers, appearance of the two N-H protons of amide groups around 10.00-11.00 ppm indicate two different amide groups in the polymer's chain. The absorption of aromatic protons appeared at a range of $7.00-8.50 \mathrm{ppm}$. The proton of the chiral center appeared at $4.63 \mathrm{ppm}$. The peak of $\mathrm{C}-\mathrm{H}$ isopropyl group of $\mathrm{S}$-valine appeared at $2.80 \mathrm{ppm}$ as a multiple peak. The absorption of the two diastrotopic $\mathrm{CH}_{3}$ protons groups of S-valine appeared around 1.00 and $1.15 \mathrm{ppm}$. Solubility of the PAs. One of the main objectives of this study was producing modified PAs with improved solubility. The incorporation of bulky side (pendent) groups into the monomer, reduces molecular packing, and restricts the formation of interchain hydrogen bonds, which are responsible of the PAs intractability. Because of flexible bulky groups in polymer's pendent, these polymers are expected to have higher solubility.

The solubility of PAs was tested at a concentration of 0.5 $\mathrm{g} / \mathrm{dL}$ and at ambient temperature in various solvents. Almost all of the PAs are soluble in organic polar aprotic solvents such 


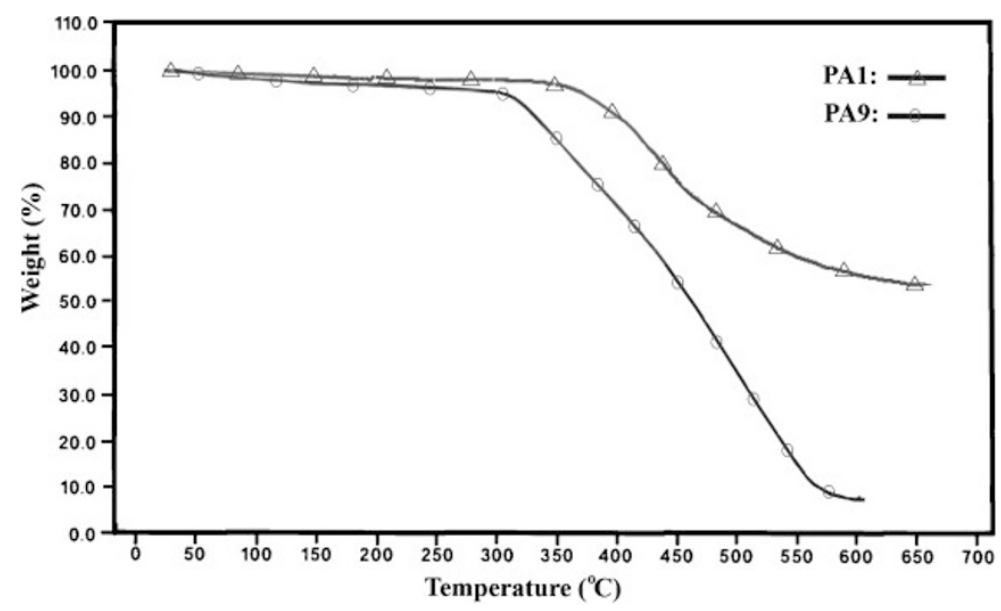

Figure 3. TGA thermograms of PA1 and PA9 under $\mathrm{N}_{2}$ atmosphere and a heating rate of $10^{\circ} \mathrm{C} / \mathrm{min}$.

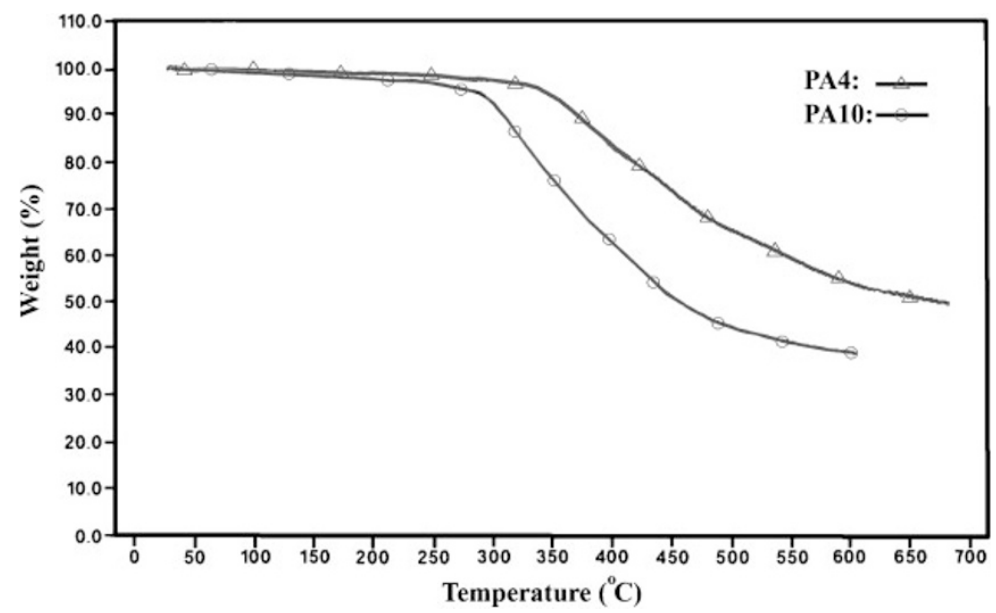

Figure 4. TGA thermograms of PA4 and PA10 under $\mathrm{N}_{2}$ atmosphere and a heating rate of $10^{\circ} \mathrm{C} / \mathrm{min}$.

as DMF, $N, N$-dimethylacetamide, dimethyl sulfoxide, NMP and polar protic solvent such as $\mathrm{H}_{2} \mathrm{SO}_{4}$ at room temperature, and are insoluble in solvents such as chloroform, methylene chloride, methanol, ethanol and water.

Thermal Properties. To get insight the thermal stability of this series of PAs, thermal properties of PA1, PA4, PA9 and PA10 were evaluated by means of TGA in a nitrogen atmosphere at a heating rate of $10{ }^{\circ} \mathrm{C} / \mathrm{min}$. The thermal stability of the polymers were assessed based on initial decomposition temperatures $\left(T_{\mathrm{i}}\right)$, temperature of $5 \%\left(T_{5}\right)$ and $10 \%\left(T_{10}\right)$ weight loss together with weight residue at $600{ }^{\circ} \mathrm{C}$. Figure 3 shows the TGA thermograms of PA1 and PA9 and Figure 4 shows the TGA thermograms of PA4 and PA10 which indicate single step thermal degradation. The thermoanalysis data of these polymers are summarized in Table V. Comparison of thermogerams of PA1 with PA9 and PA4 with PA10 demonstrate that the obtained polymers from ILs media method show higher $T_{\mathrm{i}}$, $T_{5}, T_{10}$ and char yields than PAs via phosphorylation reaction with the same diamines. So polymerizations in ILs, in addition of other advantages, give PAs with improved thermal stability.
Table V. Thermal properties of typical PAs

\begin{tabular}{ccccc}
\hline $\begin{array}{c}\text { Polymer } \\
\text { Code }\end{array}$ & $T_{\mathrm{i}}^{\mathrm{a}}\left({ }^{\circ} \mathrm{C}\right)$ & $T_{5}^{\mathrm{b}}\left({ }^{\circ} \mathrm{C}\right)$ & $T_{10}^{\mathrm{c}}\left({ }^{\circ} \mathrm{C}\right)$ & ${\text { Char Yield }(\%)^{\mathrm{d}}}$ \\
\hline PA1 & 342 & 370 & 405 & 57 \\
PA4 & 320 & 345 & 378 & 55 \\
PA9 & 295 & 304 & 338 & 8 \\
PA10 & 245 & 285 & 322 & 41 \\
\hline
\end{tabular}

a Initial decomposition temperature. ${ }^{\mathrm{b}}$ Temperature at which $5 \%$ weight loss was recorded by $\mathrm{TGA}$ at heating rate of $10^{\circ} \mathrm{C} / \mathrm{min}$ under $\mathrm{N}_{2}$ atmosphere. ${ }^{\mathrm{C}}$ Temperature at which $10 \%$ weight loss was recorded by TGA at heating rate of $10^{\circ} \mathrm{C} / \mathrm{min}$ under $\mathrm{N}_{2}$ atmosphere. ${ }^{\mathrm{d}}$ Weight percent of the material left undecomposed after TGA at maximum temperature $600^{\circ} \mathrm{C}$ in a $\mathrm{N}_{2}$ atmosphere.

The TGA measurement of the polymers revealed that these polymers exhibited good thermal stability. PA1 and PA4 are stable up to $350{ }^{\circ} \mathrm{C}$.

The introducing of heat resistant phthalimide groups as well as the presence of imide and amide group may counterbalance any loss of thermal stability that may cause by the existence of flexible aliphatic group. 


\section{CONCLUSIONS}

In this work ILs in the presence of TPP were effectively used as a condensing agent for direct polyamidation reaction of chiral aromatic 5-(2-phthalimidyl-3-methylbutanoylamino)isophthalic acid (1) with various diamines. Dicarboxylic acid $\mathbf{1}$ has a rigid phthalimide and flexible S-valine groups. In this method ILs act both as a media as well as catalyst for these polyamidation reactions. The main advantage of this method of polycondensation reaction is that, in this procedure there is no need of using volatile and toxic solvents and extra materials, consequently, would have less waste treatment after work-up. In addition, this method is one-pot reaction and It is not required to prepare diacid chloride and therefore, saves time and energy. Two typical PAs were also prepared via method II, using NMP/TPP/Py as a condensing agent. The results herein, show that ILs as a condensing media gave polymers with higher yields and inherent viscosity than phosphorylation reaction method. In addition, thermogravimetric analyses demonstrate that these PAs from ILs method have higher thermal stability in compare with PAs prepared by method II. The resulting PAs have S-valine in polymer chain and are optically active. The introduction of pendent bulky groups along the polymer backbone results in a less ordered polymer matrix hence disturbed the strong interchain and intrachain hydrogen bonding and inherent macromolecular rigidity, consequently increasing the solubility characteristics without affecting thermal properties to any great extent. These PAs could be considered as new processable high-performance polymeric materials. In addition because of the existence of amino acid in the polymer pendent group these polymers are expected to be biodegradable and therefore are classified under environmentally friendly polymers. Since the resulting polymers are optically active and have good thermal stability they have potential to be used as a chiral stationary phase in chromatography technique for the separation of chiral mixtures.

Acknowledgment. We wish to express our gratitude to the Research Affairs Division Isfahan University of Technology (IUT), for financial support. Further financial support from Center of Sensors and Green Chemistry Research (IUT) is gratefully acknowledged.

Received: September 27, 2007 Accepted: February 22, 2008 Published: May 2, 2008

\section{REFERENCES}

1. T. Welton, Chem. Rev., 99, 2071 (1999).

2. K. Binnemans, Chem. Rev., 107, 2592 (2007).
3. V. I. Parvulescu and C. Hardacre, Chem. Rev., 107, 2615 (2007).

4. H. Olivier-Bourbigou and L. Magna, J. Mol. Catal. A: Chem., 182183, 419 (2002).

5. J. Ding and D. W. Armstrong, Chirality, 17, 281 (2005).

6. C. Chiappe and D. Pieraccini, J. Phys. Org. Chem., 18, 275 (2005).

7. P. Kubisa, Prog. Polym. Sci., 29, 3 (2004).

8. L. Cheng, Y. Zhang, T. Zhao, and H. Wang, Macromol. Symp., 216, 9 (2004).

9. S. Ding, H. Tang, M. Radosz, and Y. Shen, J. Polym. Sci., Part A: Polym. Chem., 42, 5794 (2004).

10. Y. L. Zhao, J. M. Zhang, J. Jiang, C. F. Chen, and F. Xi, J. Polym. Sci., Part A: Polym. Chem., 40, 3360 (2002).

11. R. Marcilla, M. de Geus, D. Mecerreyes, C. J. Duxbury, C. E. Koning, and A. Heise, Eur. Polym. J., 42, 1215 (2006).

12. S. Mallakpour and Z. Rafiee, Eur. Polym. J., 43, 5017 (2007).

13. S. Mallakpour and Z. Rafiee, Polymer, 48, 5530 (2007).

14. S. Mallakpour and E. Kowsari, J. Polym. Sci., Part A: Polym. Chem., 43, 6545 (2005).

15. P. E. Cassidy, "Thermally Stable Polymers," Dekker, New York, 1980.

16. M. Yamashita, M. Kakimoto, and Y. J. Imai, J. Polym. Sci., Part A: Polym. Chem., 31, 1513 (1993).

17. C. Yang and W. J. Chen, J. Polym. Sci., Part A: Polym. Chem., 31, 1571 (1993).

18. S. Mallakpour and E. Kowsari, Polym. Adv. Technol., 16, 732 (2005).

19. D. J. Liaw and B. Y. Liaw, Polymer, 42, 839 (2001).

20. S. Nakata and J. J. Brisson, J. Polym. Sci., Part A: Polym. Chem., 35, 2379 (1997).

21. D. J. Liaw, B. Y. Liaw, and C. M. Yang, Macromol. Chem. Phys, 202, 1866 (2001)

22. D. J. Liaw, P. N. Hsu, and B. Y. Liaw, J. Polym. Sci., Part A: Polym. Chem., 39, 63 (2001).

23. S. Mallakpour and M. Kolahdoozan, e-Polymers, no 020 (2006).

24. S. Mallakpour and M. Kolahdoozan, J. Appl. Polym. Sci., 104, 1248 (2007).

25. S. Mallakpour and M. Kolahdoozan, Des. Monomers Polym., 10, 439 (2007).

26. S. Mehdipour-Ataei, Eur. Polym. J., 41, 65 (2005).

27. S. Mallakpour and M. Kolahdoozan, Iran. Polym. J., 15, 307 (2006).

28. V. Calderon, F. Garcia, J. L. de la Pena, E. M. Maya, A. E. Lozano, J. G. de la Campa, J. de Abajo, and J. M. Garcia, J. Polym. Sci., Part A: Polym. Chem., 44, 4063 (2006).

29. E. Ferrero, J. F. Espeso, J. G. de la Campa, J. de Abajo, and A. E. Lozano, J. Polym. Sci., Part A: Polym. Chem., 40, 3711 (2002).

30. V. Ayala, E. M. Maya, J. M. Garcia, J. G. de la Campa, A. E. Lozano, and J. de Abajo, J. Polym. Sci., Part A: Polym. Chem., 43, 112 (2005).

31. S. H. Hsiao, C. P. Yang, C. W. Chen, and G. S. Liou, Eur. Polym. J., 41, 511 (2005).

32. I. Sava and M. Bruma, Macromol. Symp., 239, 36 (2006).

33. J. M. Garcia, F. Garcia, R. Sanz, J. G. de la Campa, A. E. Lozano, and J. de Abajo, J. Polym. Sci., Part A: Polym. Chem., 39, 1825 (2001).

34. E. Hamciuc, C. Hamciuc, I. Sava, and M. Bruma, Eur. Polym. J., 37, 287 (2001).

35. A. Banihashemi and H. Firoozifar, Eur. Polym. J., 39, 281 (2003).

36. S. Itsuno, Prog. Polym. Sci., 30, 540 (2005).

37. J. J. L. M. Cornelissen, A. E. Rowan, R. J. M. Nolte, and N. A. J. M. Sommerdijk, Chem. Rev., 101, 4039 (2001).

38. Y. Okamoto, Prog. Polym. Sci., 25, 159 (2000).

39. A. Dobashi, S. Nishida, K. Kurata, and M. Hamada, Anal. Sci., 18, 35 (2002).

40. S. Mallakpour and M. Kolahdoozan, Eur. Polym. J., 43, 3344 (2007). 